\title{
The Kyoto Mechanisms and Technological Innovation
}

\author{
Henrik Lund* \\ Department of Development and Planning \\ Aalborg University, Denmark \\ e-mail: lund@plan.auc.dk
}

\begin{abstract}
Climate change response, including implementation of the Kyoto targets as the first step, calls for technological innovation of future sustainable energy systems. One of the important agreements in several declarations, including the Kyoto protocol, has been to promote and coordinate the collaboration between the countries in the necessary technological development.
\end{abstract}

Meanwhile, the Kyoto protocol introduced three new instruments, known as the Kyoto mechanisms, allowing industrialised countries to reach their targets by being involved in $\mathrm{CO}_{2}$ emission control in other countries instead of controlling their own emissions. Such instruments could intensify the collaboration on technological innovation. However, it has been feared that these new instruments would rather be used by industrialised countries to neglect their part of the agreement, which would then lead to a slowdown in technological development.

Based on the Danish case this paper evaluates the type of necessary technological change. During a period of 30 years Denmark has managed to stabilise primary energy supply and $\mathrm{CO}_{2}$ emission has been decreased by 10 per cent during a period of 20 years.

After the introduction of the Kyoto mechanisms, Denmark has changed strategy. Instead of continuing domestic $\mathrm{CO}_{2}$ emission controls, Denmark plans to buy $\mathrm{CO}_{2}$ reductions in other countries. Consequently the innovative technological development has been changed.

This paper evaluates the character of such change and makes preliminary recommendations for policies to encourage that the Kyoto mechanisms will be used for acceleration of the necessary technical innovation.

\section{UN CLIMATE CHANGE POLICIES AND THE KYOTO MECHANISMS}

At the United Nations Conference on Environment and Development in Rio de Janeiro in 1992 more than 150 governments including the major industrial and developing countries agreed on a framework convention on climate change. The objective of the convention is to stabilise the concentration of greenhouse gases in the atmosphere at a level that prevents changes to the climate caused by mankind. Greenhouse gases, especially carbon dioxide, are expected slowly to cause increased temperatures on earth.

${ }^{*}$ Corresponding author 
The main idea of the convention was to establish a framework for dealing with climate change policies. Thus the convention established a secretariat and committed the parties to collect information on greenhouse gas emissions, conduct action plans to avoid climate change and inform the other parties on such initiatives.

In addition to the establishment of the framework, the industrialised countries committed themselves to conduct policies to limit their emissions of greenhouse gases with the objective of stabilising $\mathrm{CO}_{2}$ emission by the end of the century at the level of 1990 [1].

The Rio 92 convention was based on long negotiations and previous UN conferences. One of the key documents was "Our Common Future", the report from the World Commission on Environment and Development from 1987, known as the "Brundtland report" [2].

The Brundtland report describes the growth in both population and resources such as the burning of fossil fuels. (See figure 1).

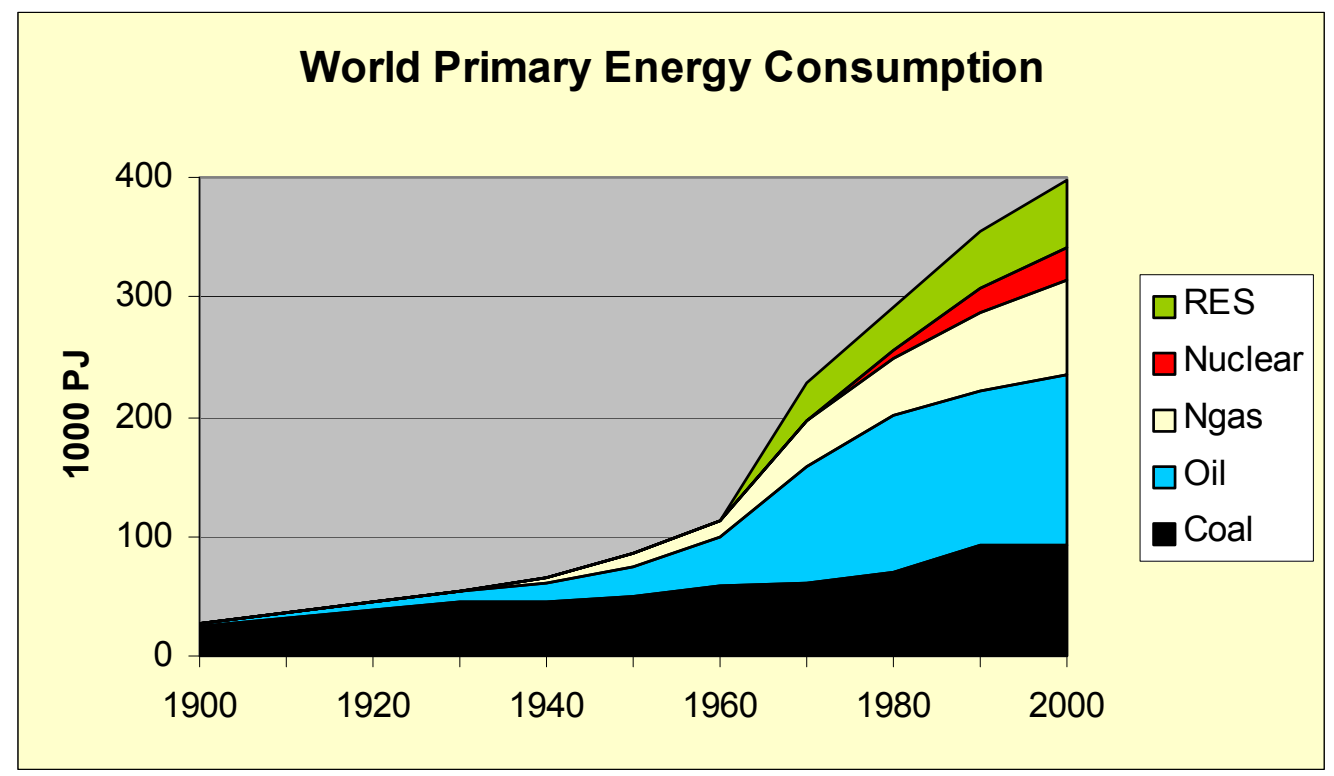

Figure 1. World primary energy supply [3, 4].

The Brundtland report emphasises the differences in the primary energy supply between the industrialised and the developing countries (See figure 2). In 1984, 25 per cent of the world population consumed 70 per cent of the total energy supply, while the remaining 75 per cent of the population were left with 30 per cent. If the total population were to have the same consumption pr inhabitant as the OECD countries in average, it would result in an increase in the 1984 demand from $10 \mathrm{TW}$ to approximately $30 \mathrm{TW}$. An expected increase in the population from 4.7 billion in 1984 to 8.2 billion in 2020 would even raise the figure to $50 \mathrm{TW}$.

The Brundtland report presents two different scenarios: A high-energy scenario and a low energy scenario. The high-energy scenario represents a 2030 "business as usual" situation resulting in a demand of $35 \mathrm{TW}$. Both from the viewpoint of resources and climate change this is considered a highly risky future development. And consequently the Brundtland report recommends the low energy scenario resulting in a world energy demand of $11 \mathrm{TW}$ in year 2020. According to this scenario the industrialised countries are supposed to cut there demand from $7 \mathrm{TW}$ in 1984 to 4 TW in 2020 leaving room for the developing countries to increase there demand from 3 TW in 1984 to 7 TW in year 2020 . 


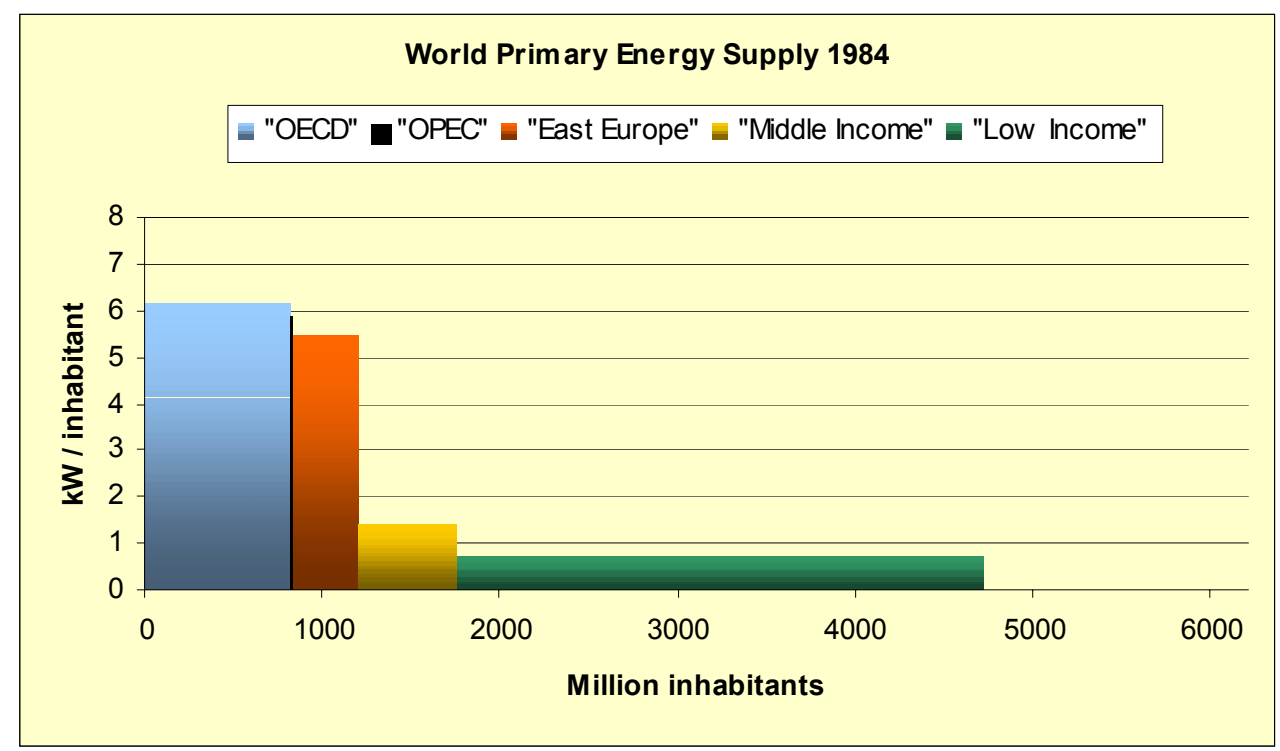

Figure 2: Distribution of the world primary energy supply in 1984 [2, 3].

So far the development of the world energy demand has not followed the low energy scenario of the Brundtland report (See figure 3). The total demand has increased from $10 \mathrm{TW}$ in 1984 to 12.6 TW in 1998. The average consumption of the OECD countries has increased from 6.2 $\mathrm{kW} /$ inhabitant to $7.1 \mathrm{~kW} /$ inhabitant, while the average of the former East European countries has decreased from 5.5 to $3.8 \mathrm{~kW} /$ inhabitant. The population in the industrialised countries has only increased slightly from 1.2 to 1.3 billion. In the developing countries both average demand and population has increased resulting in at total increase of the demand from 2.9 TW in 1984 to 4.8 TW in 1998.

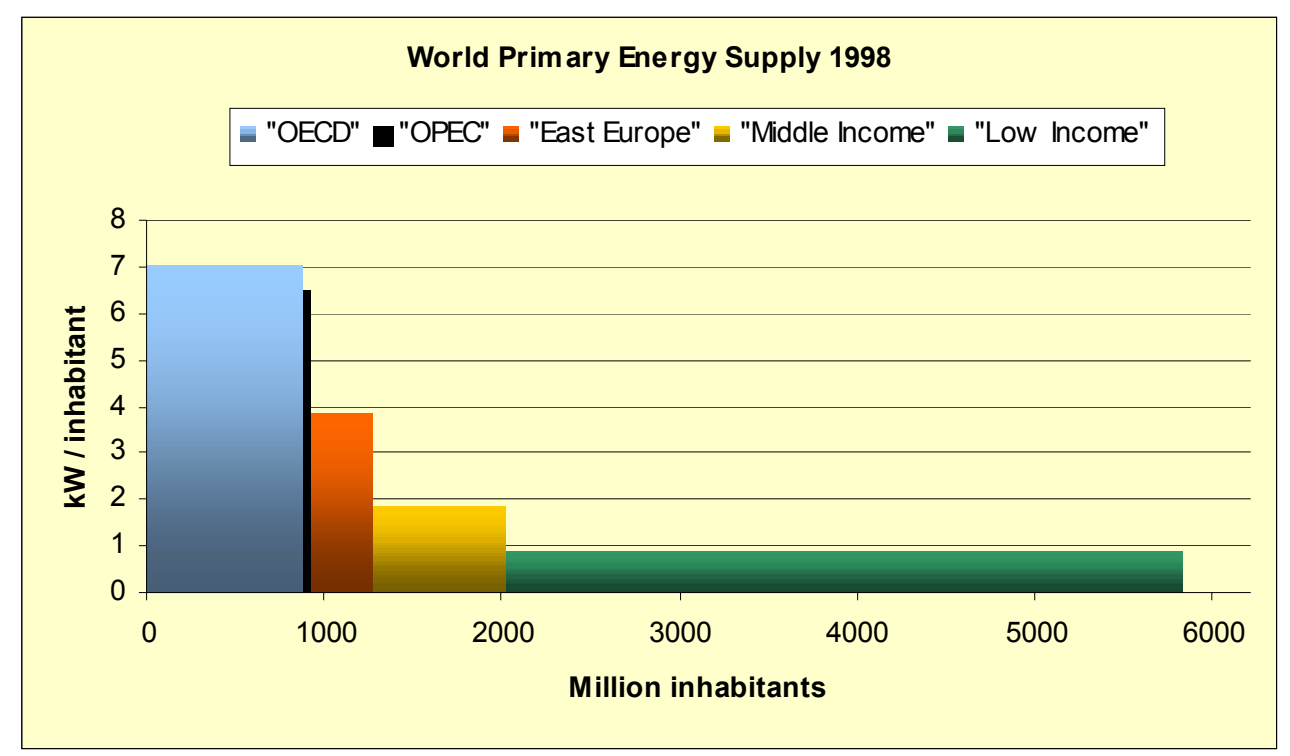

Figure 3: Distribution in world primary energy supply in 1998 [3].

In the Rio declaration the industrialised countries committed themselves to slow down their emission of greenhouse gases. Thus this first step was in accordance with the recommendations of the Brundtland report. 
The Kyoto protocol [5] from 1997 divides the parties into "Annex B countries" (similar to industrialised countries) and "Non- Annex B countries" (similar to developing countries). Following the recommendations from the Brundtland report and the first steps of the Rio declaration, the Annex $\mathrm{B}$ countries are obliged to reduce their $\mathrm{CO}_{2}$ emissions by specific numbers. The non -Annex B countries are allowed to increase their energy demand, but have agreed to pay attention to the $\mathrm{CO}_{2}$ emission and reduce as much as possible.

Meanwhile, in the Kyoto Protocol a number of new instruments, known as the Kyoto mechanisms, were introduced. Until then the industrialised countries were supposed to implement decreases in energy supply and $\mathrm{CO}_{2}$ emissions within their own domestic supply. Meanwhile the Kyoto protocol introduced three ways of fulfilling the obligations of the industrialised countries (Annex B parties) by decreasing $\mathrm{CO}_{2}$ emissions somewhere else.

The three mechanisms are:

1. Trade with quotas (article 6) between Annex B countries, including the very huge available quotas in the former Soviet countries.

2. Joint implementation: Implementation of projects in one Annex B country (East European) financed by another Annex B country.

3. Clean development mechanism (CDM) (article 12): Implementation of projects in NonAnnex B countries financed by Annex B countries.

The Kyoto mechanisms makes it possible for industrialised (Annex B) countries to buy quotas or finance projects in other countries instead of decreasing their own $\mathrm{CO}_{2}$ emission.

\section{YEARS OF DANISH SUCCESS}

Denmark is an Annex B country, which has made a radical change in strategy after the introduction of the Kyoto mechanisms. Before the Kyoto protocol, Denmark was conducting a policy of decreasing $\mathrm{CO}_{2}$ emissions by decreasing the domestic burning of fossil fuels. Energy security and climate change responses were major objectives for Danish energy policy. These objectives have been expressed through various energy plans adopted by the Danish Parliament [6].

But after the Kyoto protocol, the new Danish Government has changed strategy. Based on the expectation of very low cost of implementing $\mathrm{CO}_{2}$ emissions (5-8 EUR/ton) outside Denmark and/or buying quotas, the plan is to increase domestic $\mathrm{CO}_{2}$ emissions instead of decreasing it.

This is a very radical change to the Danish energy policy. Through nearly three decades Denmark has been able to stabilise the primary energy supply. Today the energy consumption is the same as in 1972 when the first oil crisis started. (See figure 4). The figure illustrates how a situation of complete oil dependency in 1972 has been changed into a differentiated fuel supply including a high per cent of natural gas and renewable energy sources. This was achieved in a period of normal economic growth. Consequently Denmark has been able to disconnect growth in wealth and energy demand. (See figure 5).

In the same period Denmark has begun to exploit domestic oil and gas resources, and replaced oil by coal, natural gas and renewable energy, so that today Denmark is self-sufficient in oil and gas. Renewable energy sources constitute more than 10 per cent of the primary energy supply, and wind power produces more than 15 per cent of the electricity demand. 


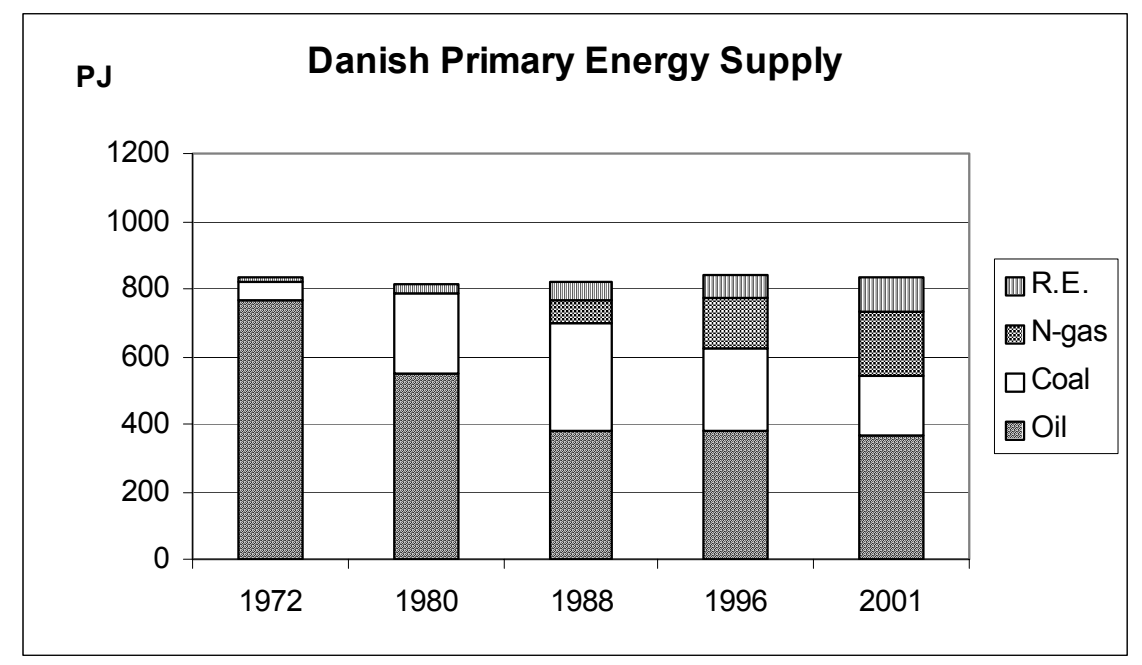

Figure 4: Primary energy supply in Denmark

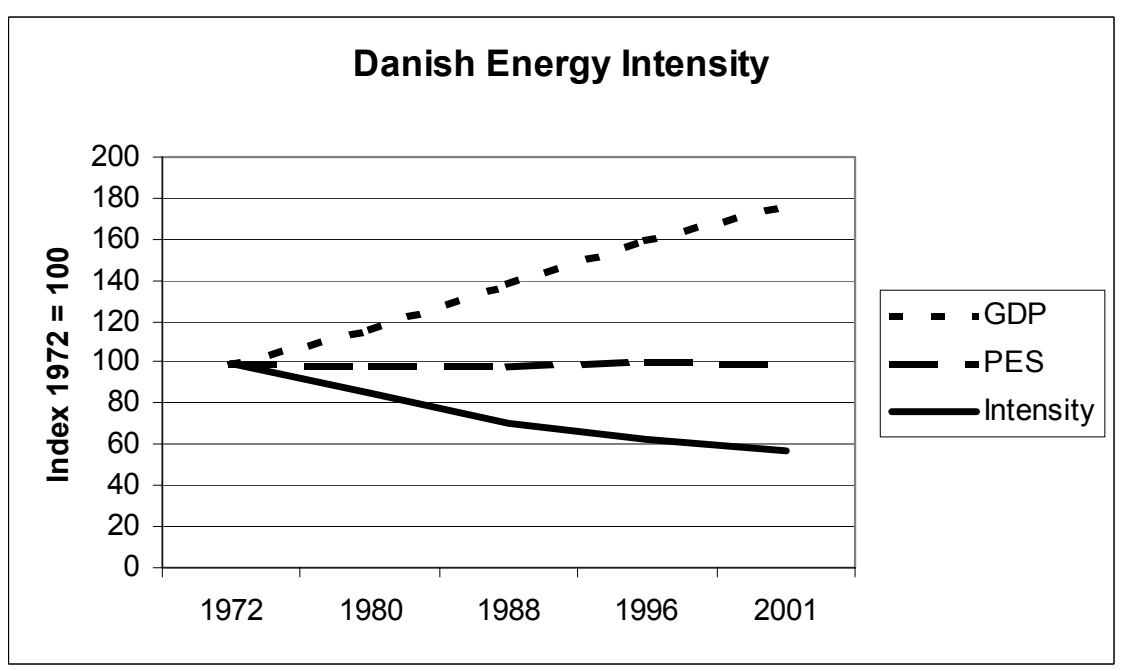

Figure 5: Danish Energy Intensity.

$(\mathrm{GDP}=$ Gross Domestic Product, PES $=$ Primary Energy Supply, and Intensity $=$ GDP/PES $)$.

Both stabilisation in energy demands and the expansion of renewable energy sources have lead to a minor decrease in the emission of greenhouse gases in Denmark. As shown in figure 6 the actual Danish $\mathrm{CO}_{2}$ emission has been fluctuating because of differences in weather conditions and import/export of electricity. When corrected from such fluctuations the $\mathrm{CO}_{2}$ emission has decreased from 61,1 Mt in 1980 to 53,8 $\mathrm{Mt}$ in 2001. Compared to the total greenhouse gas emission of $78 \mathrm{Mt} \mathrm{CO}_{2}$-equivalent the emission has decreased by nearly 10 per cent during a period of 20 years.

According to the Kyoto protocol (annex B) the EU countries have committed themselves to reduce the greenhouse gas emission by 8 per cent in average. And according to the internal burden sharing of EU, Denmark is committed to reduce by 21 per cent [7]. Meanwhile it has never been totally clear, if the Danish reference year 1990 is the actual emission or the import/export corrected emission. Since Denmark imported quite a lot of electricity in 1990 this has turned out to be very important. Compared to the corrected figure the Danish target is 45 $\mathrm{Mt} /$ year, while compared to the actual emission the target is $40 \mathrm{Mt} / \mathrm{year}$. Both targets are illustrated in figure 6 . 


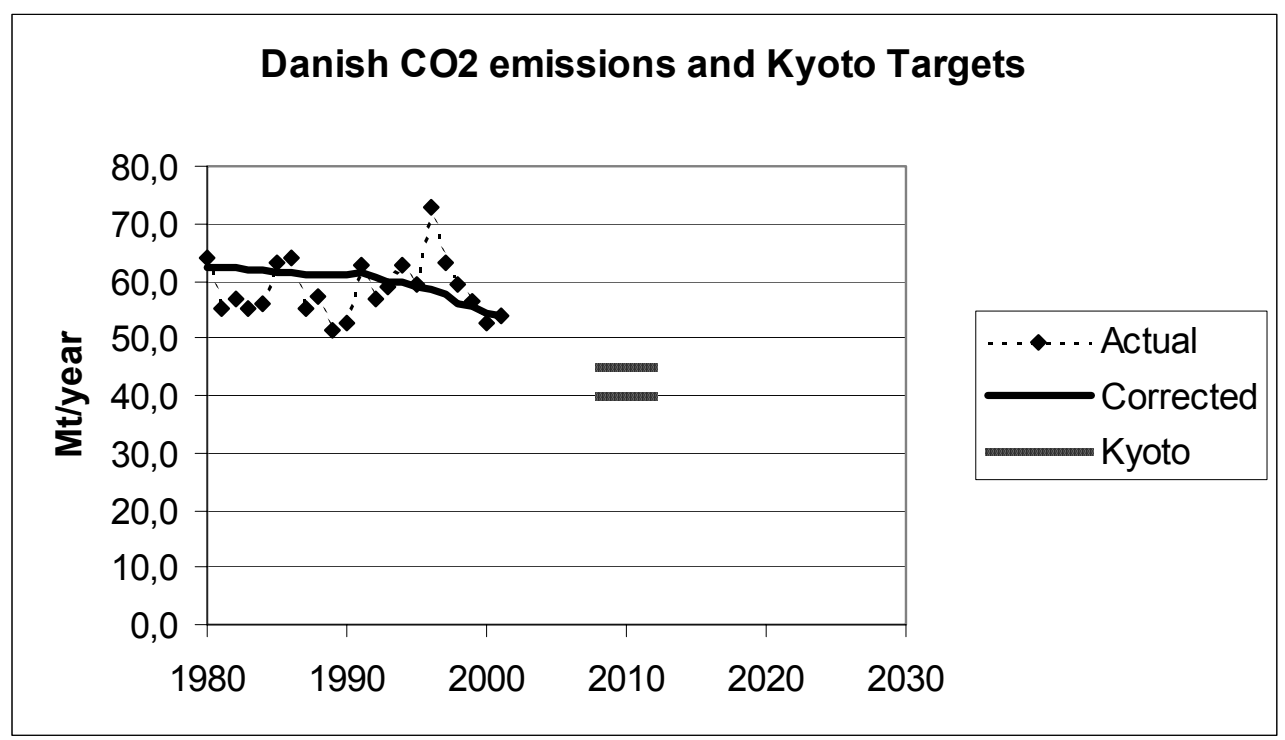

Figure 6: Actual and corrected (climate and import/export) Danish $\mathrm{CO}_{2}$ emissions compared with the Kyoto targets year 2008-2010.

Until recently it was the policy of the Danish parliament to implement the Kyoto target by reducing $\mathrm{CO}_{2}$ emissions according to the official energy plan "Energy 21" [8]. Energy conservation and an increase in the share of renewable energy sources are the primary instruments. The implementation of Energy 21 would lead to a fulfilment of the Kyoto targets in year 2010 and a 50 per cent reduction in $\mathrm{CO}_{2}$ emissions in year 2030 (See figure 7).

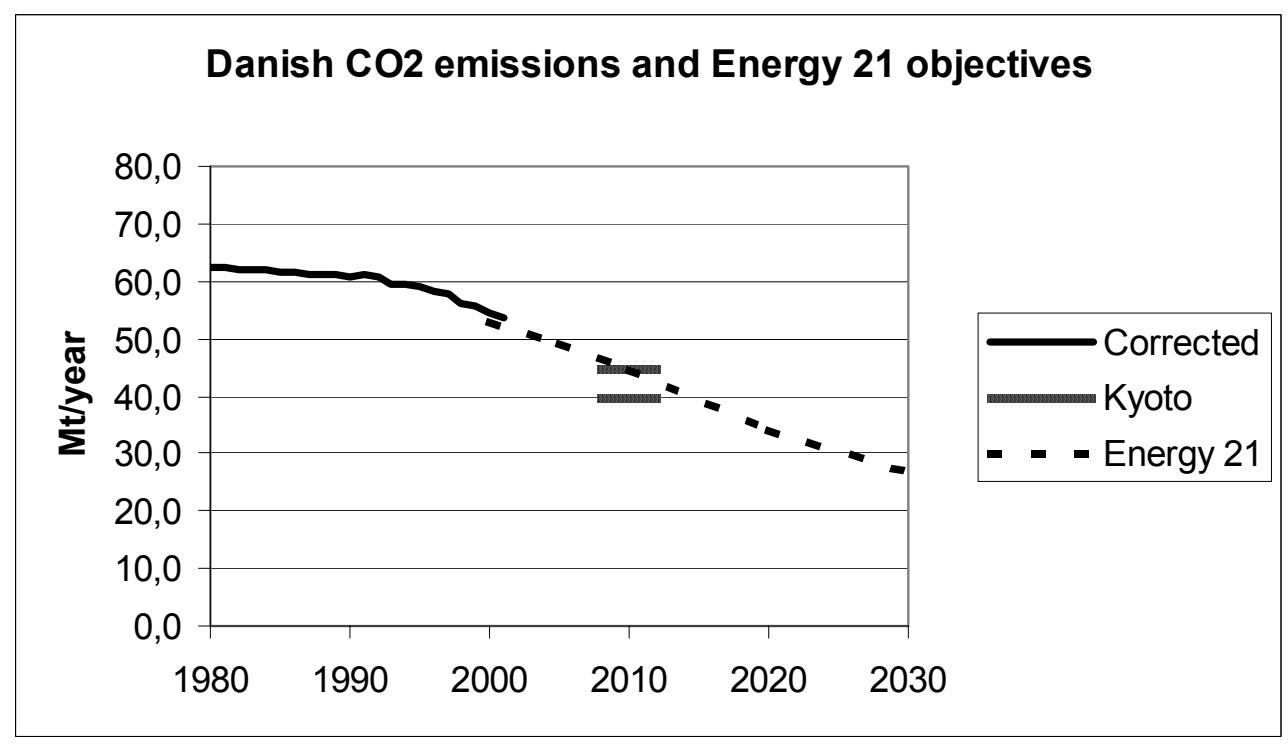

Figure 7: Planned decrease in Danish $\mathrm{CO}_{2}$ emissions according to the former Danish Parliament energy plan "Energy 21" [8].

\section{THE CHARACTER OF TECHNOLOGICAL CHANGE}

The implementation of technological change in the Danish energy system has been based on the principles of emphasising energy conservation, expansion of combined heat and power production (CHP) and increasing the share of renewable energy. Opposed to the former 
technologies, these new technologies are widely distributed throughout the areas of consumption and therefore have been characterised by the following.

The implementation of new technologies has been carried out by multipurpose organisations. Electricity savings had to be implemented by private households and industries with other main objectives and with little interest in electricity consumption. In the former situation investments in supply technologies were carried out by single-purpose organisations such as utility companies and gas supply companies.

Investments were implemented by many independent organisations, and technical solutions differ from one place to another. Sometimes new and partly unsafe and not well-proved technologies were implemented. Maintenance of such new technologies depends on the ownership and organisation. Along with the implementation of new technologies new types of organisations emerged. Maintenance of biogas plants and straw fired district heating systems, for example, resulted in new organisations in which corporations of farmers own the production facilities while corporations of district heating consumers own the distribution facilities.

Altogether, the technological change was characterised by a change from undifferentiated solutions implemented by few single-purpose organisations into differentiated solutions implemented by many multipurpose organisations. For more information consult [9].

These technologies are also characterised by the fact that they are long lasting, if not ever lasting. Fossil fuels are limited in time. But energy conservation-, CHP- and renewable energy measures have everlasting potentials.

\section{THE CHANGE IN DANISH CLIMATE CHANGE POLICIES}

In February 2003 the new Danish Government issued a new climate change policy based on an extensive use of the Kyoto Mechanisms. According to the analyses behind the new policy the $\mathrm{CO}_{2}$ emission in year 2010 is expected to increase from $54 \mathrm{Mt}$ in 2001 to $65 \mathrm{Mt}$ in 2010. The reference scenario is compared with the former "Energy 21" strategy in figure 8.

According to the new climate strategy a Danish least cost implementation of a mixture of domestic reductions and the use of Kyoto mechanisms should be identified and implemented. From analysing the potential of buying $\mathrm{CO}_{2}$ quotas from former Soviet countries, and such quotas' influence on the world market prices of Kyoto mechanisms, prices between 40 and 60 DDK/ton $\mathrm{CO}_{2}$ (5-8 EUR/ton) are expected. Only very few domestic measures can compete with such price levels. And the potential of implementing long term everlasting technologies like mentioned above is very little.

Among the domestic technologies that may have a chance is replacement of coal with natural gas and injection of $\mathrm{CO}_{2}$ into oil fields, both being characterised by high short term potentials but with limited potentials in the long term. Innovative sustainable technologies such as renewable energy, further expansion of CHP and energy conservation are hardly included in the strategy. For example further investments in offshore wind farms are considered too expensive and should be stopped according to the analysis in the strategy. 


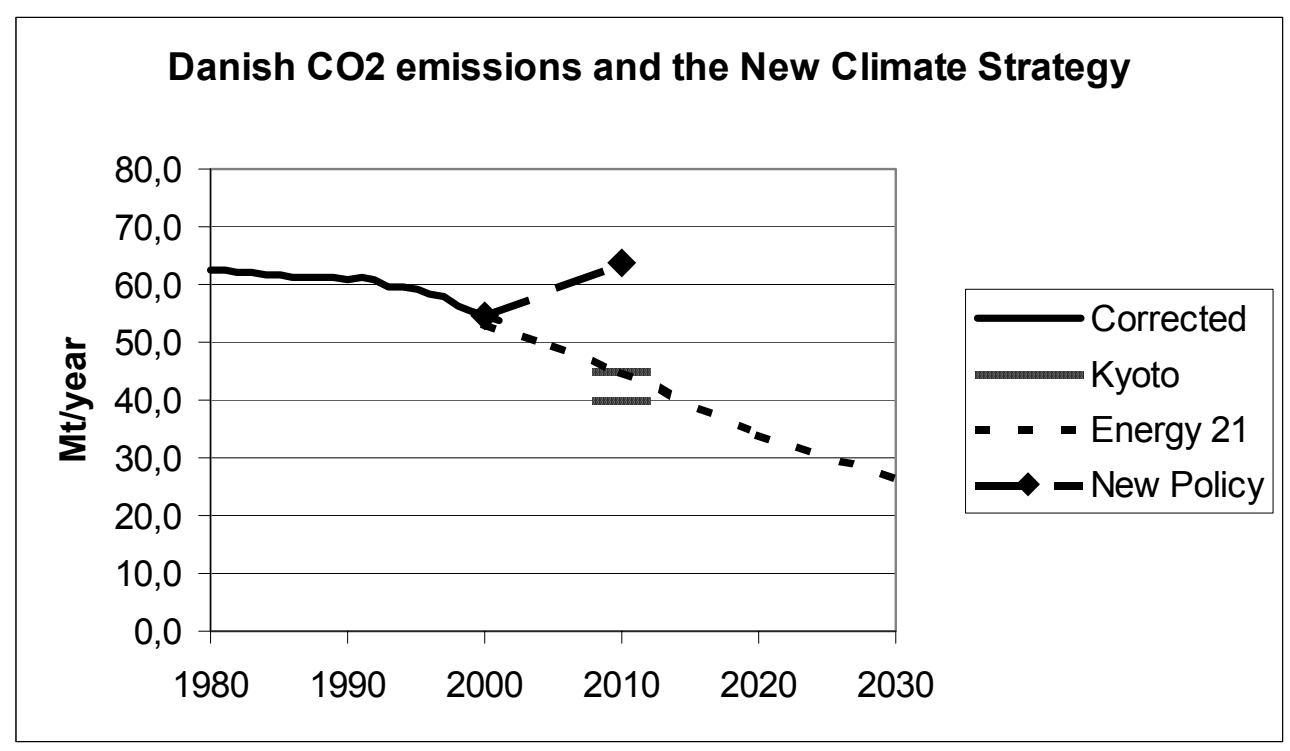

Figure 8: New Danish reference $\mathrm{CO}_{2}$ emission compared with former "Energy 21" policy.

Consequently, the strategy will result in a delay in the development of technological innovation of future sustainable energy systems. Instead the strategy finds it more cost effective to buy $\mathrm{CO}_{2}$ quotas and take advantage of CDM and joint implementation projects.

\section{CONCLUSION AND RECCOMMENDATIONS}

Introduced in the Kyoto Protocol in 1997 and emphasised in the Johannesburg summit in 2002 the CDM and the principle of Joint Implementation together with quota trade has come to play a major role in the implementation of GHG emission controls. In industrialised countries there is a tendency to change strategies. Instead of implementing cleaner technologies, some industrialised countries consider to fulfil obligations by investing in CDM and joint implementation in other countries.

Denmark seems to be an example. For 30 years Denmark has pursued an Energy Policy of implementing cleaner technologies in Denmark showing remarkable results on the international scene. Energy conservation measures and the expansion of Combined Heat Power (CHP) production have decreased demands. And natural gas and renewable energy sources have replaced the use of oil and coal, including the expansion of wind power to cover more than $15 \%$ of Danish electricity supply. As a result the primary energy supply has been stabilised over a period of more than 30 year. And Denmark was in the process of fulfilling $\mathrm{CO}_{2}$ emission reduction obligations according to international agreements within EU and in the Kyoto protocol.

Until recently the Danish energy policy has aimed at continuing the strategy of cleaner technologies. Meanwhile in 2002 the Danish Government stopped a number of energy efficiency initiatives, and in $2003 \mathrm{CDM}$ and joint implementation have been proposed as instruments to meet international agreements instead. Consequently the primary energy supply and $\mathrm{CO}_{2}$ emission will increase again in Denmark.

If such strategies were to be conducted by industrialised countries in general it would influence the world development in a direction opposite to the recommendations of the 
Brundtland report. Industrialised countries will raise their energy demand and $\mathrm{CO}_{2}$ emission instead of decreasing it. And obligations to reduce $\mathrm{CO}_{2}$ emissions will be fulfilled first by buying quotas in the former Soviet countries and secondly by use of CDM and Joint Implementation in the developing countries. Such strategy will either be unsuccessful in reducing energy demands and $\mathrm{CO}_{2}$ emissions or it will increase the difference between the rich and the poor countries instead of decreasing it.

Furthermore, Climate Change response calls for intensive technological innovation of future sustainable energy systems. And such innovative technological development will suffer from the strategy.

\section{REFERENCES}

1. United Nations, "Rio Declaration on Environment and Development", Rio de Janeiro, 3-14 June 1992.

2. United Nations, "Our Common Future, report from the World Commission on Environment and Development", Oxford University Press, 1987.

3. International Energy Agency "Energy Balances 1997-1998", Paris, 2000.

4. World Energy Council.

5. United Nations "Kyoto Protocol to the United Nations Framework Convention on Climate Change", Kyoto 1997.

6. Lund, H. (2000) 'Choice Awareness: The Development of Technological and Institutional Choice in the Public Debate of Danish Energy Planning', Journal of Environmental Policy \& Planning 2:249-259.

7. Commission of the European Communities, (2002/358/EF), Brussels, April 2002.

8. Ministry of Environment and Energy "Energy 21, The Danish Government's Action Plan for Energy" Ministry of Environment and Energy, Copenhagen, Denmark, 1996.

9. Hvelplund F, Lund H, Serup K E, Mæng H, "Demokrati og forandring" (Democracy and Change), Aalborg University Press, September 1995. 